\title{
Corrigendum: Acute administration of MK-801 in an animal model of psychosis in rats interferes with cognitively demanding forms of behavioral flexibility on a rotating arena
}

\author{
Jan Svoboda ${ }^{1}$, Anna Stankova ${ }^{1,2}$, Marie Entlerova ${ }^{1}$ and Ales Stuchlik ${ }^{1,2 *}$ \\ ${ }^{1}$ Institute of Physiology Academy of Sciences, Prague, Czech Republic, ${ }^{2}$ National Institute of Mental Health, Klecany, \\ Czech Republic
}

Keywords: MK-801, rats, flexibility, active place avoidance, memory

\section{A corrigendum on}

OPEN ACCESS

Edited and reviewed by: Allan V. Kalueff,

ZENEREI Institute, USA Guangdong Ocean University, China; St. Petersburg State University, Russia

*Correspondence: Ales Stuchlik ales.stuchlik@fgu.cas.cz

Received: 23 November 2015 Accepted: 30 November 2015 Published: 16 December 2015

Citation: Svoboda J, Stankova A, Entlerova M and Stuchlik A (2015) Corrigendum: Acute administration of MK-801 in an animal model of psychosis in rats interferes with cognitively demanding

forms of behavioral flexibility on a rotating arena.

Front. Behav. Neurosci. 9:348. doi: 10.3389/fnbeh.2015.00348
Acute administration of MK-801 in an animal model of psychosis in rats interferes with cognitively demanding forms of behavioral flexibility on a rotating arena

by Svoboda, J., Stankova, A., Entlerova, M., and Stuchlik, A. (2015). Front. Behav. Neurosci. 9:75. doi: 10.3389/fnbeh.2015.00075

In the paper by Svoboda et al., a mistake was made in the Acknowledgment Section. The corrected Acknowledgments follow:

\section{ACKNOWLEDGMENTS}

This work was supported by GACR (Czech Science Foundation) 14-03627S grant awarded to AS. We thank all colleagues and laboratory assistants for their immense support. We are grateful to P. M. Luketic for proofreading services. Institutional and academic support was provided by AS CR M200111204, RVO: 67985823, and ED2.1.00/03.0078.

Conflict of Interest Statement: The authors declare that the research was conducted in the absence of any commercial or financial relationships that could be construed as a potential conflict of interest.

Copyright (c) 2015 Svoboda, Stankova, Entlerova and Stuchlik. This is an open-access article distributed under the terms of the Creative Commons Attribution License (CC BY). The use, distribution or reproduction in other forums is permitted, provided the original author(s) or licensor are credited and that the original publication in this journal is cited, in accordance with accepted academic practice. No use, distribution or reproduction is permitted which does not comply with these terms. 